\title{
On the Awareness of English Polysemous Words by Arabic- Speaking EFL Learners
}

\author{
Sulafah Abdul Salam Alnamer \\ College of Education, Humanities and Social Sciences, Al Ain University of Science and Technology, P.O. Box: 64141 Al Ain, UAE \\ E-mails: 201410607@aau.ac.ae, sulafah57@gmail.com
}

Doi:10.7575/aiac.alls.v.8n.2p.112

Received: 06/03/2017

URL: http://dx.doi.org/10.7575/aiac.alls.v.8n.2p.112

Accepted: 28/04/2017

\begin{abstract}
This study measures the extent to which Arabic-speaking EFL learners are aware of polysemy in English. It also investigates whether the English proficiency level of Arabic-speaking EFL learners plays a role in their ability to distinguish between the various meanings of English polysemous words, and whether they face problems when they encounter these words in unusual contexts (i.e. the contexts that employ the extended meanings of the target polysemous words). To these ends, a translation test in which the participants were asked to give full Arabic translation for fifteen English sentences was designed. The words open, run, and make were the target polysemous words in this study. The Results show that Arabic-speaking EFL learners have little awareness of polysemy in English, and their English proficiency level does play a role in their ability to distinguish between the different meanings of English polysemous words. It was also found that Arabic-speaking EFL learners have no problems guessing the primary meaning of the English polysemous words. However, they face difficulty guessing the extended meanings of polysemous words in unusual contexts. Moreover, some Arabic-speaking EFL learners can guess the extended meanings of the polysemous words they encounter in familiar contexts, or when they understand some cues provided to disambiguate these words. This study concludes with some pedagogical implications and recommendations for further studies.
\end{abstract}

Keywords: Polysemy, second language acquisition, Arabic-speaking EFL Learners, the primary meaning, the extended meanings.

\section{Introduction}

Vocabulary is one of the most important aspects of learning a second language (L2). It is enriched by the production of new words either by morphological means or by the development of polysemy, which is one of the general characteristic features of a language. Polysemy is a ubiquitous phenomenon whereby a word has distinct but related senses with respect to the contexts in which it is used (Makni, 2013). For example, the word good can be used to refer to something of high quality, as in 'good food', or to something pleasant, as in 'Did you have a good time in London?'. 1 Historically, the reason why polysemous words are ubiquitous is that people preferred to extend the meaning of already existing words rather than create new ones (Gyori, 2002; Murphy, 2004). Thus, polysemy is considered an essential resource of language economy, since it is very difficult to have separate terms for every referent (Ullmann, 1959: 118).

Over 40\% of English words are polysemous (McCarthy, 1997; Durkin \& Manning, 1989) most of which, as Makni (2013) maintains, belong to the three thousand most frequently used words in the language. Knowledge of frequent polysemous words is essential to form a substantial vocabulary base (Nation, 1990, 2001, 2008; Cobb, 2006). Nation $(2001,2008)$ argues that knowledge of high frequency words can help EFL learners understand about $80 \%$ of most of English texts. Furthermore, awareness of polysemous words in contexts helps EFL learners become independent and effective learners capable of deciding how to memorise various meanings of a word and choosing the appropriate meaning out of several meanings they encounter with the aid of a dictionary (Zibin \& Altakhaineh, 2014; Wei \& Lou, 2015). Therefore, it is crucially important for EFL learners to grasp and acquire knowledge of polysemous words.

As far as English polysemous words and Arabic-speaking EFL learners are concerned, little attention has been given to the acquisition of polysemy by Arabic-speaking EFL learners; there are a few studies pertaining to polysemy, but they are mostly concerned with teaching English polysemous words (Makni, 2013) and identifying problems Arabicspeaking EFL learners face in translating English polysemous words into Arabic (Hamlaoui, 2010; Salem, 2014). Therefore, this study aims to contribute to the body of research literature by investigating the acquisition of English polysemous words by Arabic-speaking EFL learners. 


\section{Literature Review}

\subsection{Polysemy}

Polysemy or polysemia is a compound noun for basic feature. This name comes from Greek poly 'many' and semy 'to do with meaning as in semantics'. Polysemy is also called radiation or multiplication. This happens when a word acquires a wider range of meanings' (Quiroge-Clare, 2003). In fact, the term polysemy was first introduced by the French semanticist Michel Bréal in his Essai de Sémantique in 1897 (Kovács, 2011). It can be defined as one form (written or spoken) having multiple meanings that are all related by extension (Yule, 2010:120). The different meanings of a polysemous word are often derived from its 'primary meaning'. The other meanings are 'the extended meanings', some of which can be peripheral due to their low frequency of use (Liu, 2013). To illustrate this point, consider the meanings of the polysemous word 'head' in the following examples2:

1) She nodded her head in agreement.

2) She resigned as head of department.

3) The president sat at the head of the table.

The primary meaning of the word 'head' is 'the part of the body on the top of the neck' as in example (1). Some of its extended meanings are 'the person who is in charge', as in example (2) and 'the most important seat at a table', as in example (3). Although these meanings are slightly different, they are related to each other in one way or another; they all denote superiority.

Since the study of polysemy has often been associated with the study of homonymy, it is necessary to draw a clear line between the studies of these two phenomena (Dash, 2010). Unlike the case in polysemy, in homonymy, different unrelated meanings are shared under the same surface form of a word (Fellbaum, 2000: 52). Consider the meanings of the word 'bank' in the following examples3:

4) My salary is paid directly into my bank.

5) He jumped in and swam to the opposite bank.

In example (4), 'bank' means 'an organisation that provides various financial services', whereas in example (5), it means 'the side of a river, canal, etc. and the land near to it'. It is noticeable that these two meanings are unrelated; hence, these two words in examples (4-5) are homonymous rather than polysemous.

It is noteworthy that the context in which a word is used determines its meaning, as sometimes it is difficult to understand the meaning of a word just by looking at its surface form or its orthography (Dash, 2008).

Since the meanings of polysemous words are determined by the context in which they occur, acquiring such words can be quite challenging for EFL learners. The next section further elucidates this point and sheds light on the difficulties facing EFL learners in acquiring polysemous words.

\subsection{Difficulties facing EFL learners in acquiring polysemous words}

According to Bensoussan and Laufer (1984), polysemous words elicited the largest number of errors in the comprehension of words by EFL learners, and their performance was worse on guessing the meanings of these words than on guessing the meanings of other words. Even the advanced learners rarely knew all the meanings of a polysemous word (Hulstijn, 1998, 2001). Armstrong (2005) points out that since the meanings of polysemous words are determined by the linguistic contexts in which they occur, this makes them 'trouble-makers' more than other words.

EFL learners find polysemous words quite problematic when they encounter them in their readings or in the classroom due to the various meanings polysemous words can convey and sometimes due to the ambiguity of the texts in which they occur. EFL learners tend to resort to the dictionary to look up the meanings of polysemous words, but the problem is that it neither provides all the meanings of polysemous words all the time nor does it illustrate their usages. Moreover, when EFL learners look up the meaning of an unfamiliar polysemous word, they encounter a number of meanings, but they do not know which one is appropriate unless they fully understand the context of that word. This understanding can be undermined by not knowing at least one word of the context (Parent, 2009).

Moreover, in reading, learners who are familiar with one meaning of a polysemous word are reluctant to abandon it even when its meaning is different in a particular context; they tend to stick to the meaning they know (Laufer, 1997). This can lead to confusion, misunderstanding of a text, or even to the misuse of the polysemous word which, in turn, can lead to miscommunication. This difficulty can be attributed to the fact that in the classroom, students are not alerted to the phenomenon of polysemy; they are taught only the word form and its primary meaning and are tested only on them, whereas the extended meanings are left to chance encounters (Parent, 2009).

\subsection{Previous studies on the acquisition of polysemous words by EFL learners}

Several studies have addressed the acquisition of polysemous words in English by EFL learners belonging to different linguistic backgrounds. For instance, Iravani and Ghasemi (2013) investigated the acquisition of English polysemous

2 The provided examples were taken from the Oxford English Dictionary: New Oxford Advanced Learner's Dictionary (Wehmeier, 2007).

3 The provided examples were taken from the Oxford English Dictionary: New Oxford Advanced Learner's Dictionary (Wehmeier, 2007). 
words by Iranian EFL learners, using two tasks: a translation task and a multiple-choice task, and three types of cues. The first cue is the elaborated-context cue, which consisted of two sentences that provided contextual information. The second cue is the semantic-frames cue, which consisted of a sentence with a verb with the same semantic frame of the target meaning. The third cue is the meaning-chains cue, which consisted of two or three sentences with one representing the core meaning and the others representing a familiar mediating meaning that connected the core sense with the target sense. These cues were designed to help learners access the target meanings. The learners found the multiple-choice task easier than the translation task. That is, they had difficulty finding an appropriate translation for the meaning they had found, and it was because, as argued by Shohamy (1984), multiple-choice tasks require comprehension and selection, while open-ended questions, of which translation is an example, test production and call for a higher level of language skills.

As far as the cues were concerned, learners who understood the cues directly accessed the target meanings, whereas those who misunderstood the cues failed to comprehend them. The results show that the cue of the elaborated context was the most helpful cue, since contextual information constitutes the major resource for guessing word meaning. The other two types of cues were less helpful in assisting the learners to link between the cue and the target word. Moreover, processing these two types of cues required more cognitive effort than processing the cue of the elaborated context (Iravani \& Ghasemi, 2013).

Kim and Choe (2015) emphasise the use of contextual cues in understanding the meaning of polysemous words in their study to measure Korean EFL learners' knowledge of polysemous words in relation to word frequency and reading proficiency. They suggest that differences in second-language (L2) learners' knowledge can be measured not only by how many individual meanings they have memorised, but also by their ability to use contextual cues. In turn, their vocabulary knowledge becomes more contextualised as their reading proficiency progresses.

In another study, Wei and Lou (2015) examine word meaning acquisition of polysemous words by Chinese English majors at different language proficiency levels (undergraduates and postgraduates). The results show that providing students with primary meaning cues can help them guess the extended meanings of unfamiliar polysemous words, but providing them with non-primary meanings make it difficult for them to guess the extended meanings of the same words. Undergraduates and postgraduates show similar acquisition effects in primary meaning but different acquisition effects in the extended ones; the scores of the postgraduates are higher than the scores of the undergraduates.

Reynolds et al. (2015) explores the extent to which seven characteristics of the English language vocabulary, such as word length, word frequency, lexicalisation, and polysemy affect the acquisition and retention of English language vocabulary by Taiwanese English major EFL learners, using the Vocabulary Size Test (VST). This test is a data collection method designed to measure English vocabulary knowledge and vocabulary size (Nation \& Beglar, 2007). Regarding polysemy, the findings of this study show that frequent polysemous words, specifically polysemous nouns, tend to be easily acquired and retained by Taiwanese English major EFL learners compared to words with other characteristics. Reynolds et al. (2015) ascribe that to the learners' exposure to English in universities, especially in Literature courses in which words are used in contexts.

Since the learning of polysemous words by non-English major learners may be quite difficult, Reynolds et al. (2015) recommend that teachers offer learners substantial amount of reading material so that learners can have more opportunities of exposure to polysemous words. They also recommend the use of 'Image-Schema-Based Instruction' (ISBI) that reinforces learners' impressions of the target polysemous words by providing the core meaning of these words with visual displays. This has been found to be as effective as the use of L1 translation (Morimoto \& Loewen, 2007: 351). Hence, Reynolds et al. (2015) suggest using ISBI together with L1 translation to promote the acquisition of polysemous words by non-English language majors.

Drawing on the previous literature, it seems that investigating the acquisition of lexical phenomena has started to gain momentum only recently, yet few studies have been conducted on the acquisition of these phenomena by Arabicspeaking EFL learners (see Zibin \& Altakhaineh, 2016; Zibin, 2016). More importantly, it is evident that the phenomenon of polysemy has paved the way to considerable research around the world. As far as this phenomenon and Arabic speaking EFL learners are concerned, some researchers shed some light on teaching English polysemous words to Arabic-speaking EFL learners (Makni, 2013), and on the problems they face when translating polysemous English words into Arabic (Hamlaoui, 2010; Salem, 2014). However, little attention has been given to exploring Arabicspeaking EFL learners' awareness of polysemous words. Therefore, this study is intended to bridge this gap by answering the following research questions:

1) To what extent are Arabic-speaking EFL learners aware of polysemy in English?

2) Does the English proficiency level of Arabic-speaking EFL learners play a role in their ability to distinguish between the different meanings of polysemous words?

3) Do Arabic-speaking EFL learners encounter difficulties with polysemous words used in unusual contexts, such as the contexts that employ the extended meanings of the target polysemous words?

\section{Methodology}

\subsection{Participants}

The participants who took part in this study were fifty students majoring in the English language at Al Ain University of Science and Technology, Al Ain, the United Arab Emirates (UAE). They were chosen randomly and divided into two groups: 25 advanced learners (ALs) and 25 intermediate learners (ILs) based on one variable, which is their English 
proficiency level. Their levels of English proficiency were determined on the basis of the modules they were taking at the time of data collection: those taking Effective Communication Skills in English 2 (English 2) were considered advanced, and generally their IELTS scores ranged between 5 and 6.5; those taking Intensive English Remedial (IRE) were considered intermediate, and generally their IELTS scores were 4 or less.

\subsection{The test}

The participants were provided with worksheets that included 15 English sentences selected from the Oxford English Dictionary: New Oxford Advanced Learner's Dictionary (Wehmeier, 2007) (see Appendix A). The polysemous words open, run, and make were the target words. Each of these words was embedded in five different contexts that gave five different meanings to each word. Table 1 below presents the polysemous words and their target meanings on the test.

Table 1. The target polysemous words and their meanings

\begin{tabular}{|c|c|}
\hline $\begin{array}{l}\text { The polysemous } \\
\text { words }\end{array}$ & Meanings \\
\hline \multirow{5}{*}{ Open } & Meaning 1: 'spread out' \\
\hline & Meaning 2: 'not covered' \\
\hline & Meaning 3: 'honest' \\
\hline & Meaning 4: 'not hidden' \\
\hline & Meaning 5: 'available’ \\
\hline \multirow{5}{*}{ Run } & Meaning 1: 'move fast' \\
\hline & Meaning 2: 'manage' \\
\hline & Meaning 3: 'provide' \\
\hline & Meaning 4: 'use' \\
\hline & Meaning 5: 'flow' \\
\hline \multirow{5}{*}{ Make } & Meaning 1: 'prepare' \\
\hline & Meaning 2: 'force' \\
\hline & Meaning 3: 'appoint' \\
\hline & Meaning 4: 'reach' \\
\hline & Meaning 5: 'represent' \\
\hline
\end{tabular}

The reason behind choosing these words was that, based on what I have observed in my university, students tend to use these three polysemous words more frequently than any other polysemous words, yet sometimes incorrectly. Thus, it can be suggested that it is important to identify the areas of difficulties EFL learners face when they encounter these words. In addition, measuring their ability to recognise the different contextual meanings these words hold is an area worthy of investigation.

Before distributing the worksheets, clear instructions about the test were given. It was important to assure the participants that their participation was voluntary, and the results of this study had no consequence on their academic achievement and programme grades. They were instructed to translate 15 English sentences in their entirety into Arabic. Although the test had only 15 items, it took the participants about 30 minutes to hand in the worksheets. It is basically because translation requires production, and hence is more difficult than some other tasks, such as a multiple-choice task (Nation, 2001; Zibin, 2016).

The focus of this test was on the content of the sentences produced by the participants. The form, translation rules, Arabic grammatical rules, and the structure of the sentences were not as important as the Arabic equivalent of the English polysemous words provided by the participants.

\subsection{Research hypotheses}

This study attempts to corroborate the following hypotheses:

Hypothesis 1 (H1): There are no statistically significant differences between the answers of the advanced learners (ALs) and those of the intermediate learners (ILs) in terms of the primary meaning (meaning\#1) of the words open, run, and make.

Hypothesis 2 (H2): There are statistically significant differences between the answers of the advanced learners (ALs) and those of the intermediate learners (ILs) in terms of the extended meanings (meaning\#2, meaning\#3, meaning\#4, and meaning\#5) of the words open, run, and make. 
In the current study, a t-test employing SPSS software package was used to demonstrate whether the differences between the participants' answers on the translation test are statistically significant. Therefore, this test provides an answer as to whether the participants' English proficiency level contributes either positively or negatively to their ability to distinguish between the different meanings of polysemous words and their productive skills of the Arabic equivalent of these meanings. This test was also used to confirm or falsify the hypotheses formulated for the purpose of this study. The next section presents the results of the present study and discusses them.

\section{Results and discussion}

\subsection{Results}

As discussed in section 3, the current study aims to test the ability of 50 Arabic-speaking EFL learners to provide the translation of English polysemous words into Arabic. It also examines whether there are differences in the performance of ALs and ILs on the translation test. Table 2 below provides a detailed analysis of the results obtained, presenting the percentages of the correct answers provided by ALs and those of the correct answers provided by ILs for each of the target meanings of the polysemous words open, run, and make.

Table 2. Percentages of the correct answers provided by both groups for each meaning

\begin{tabular}{|c|c|c|c|c|}
\hline \multirow{2}{*}{$\begin{array}{l}\text { The polysemous } \\
\text { Words }\end{array}$} & \multirow[t]{2}{*}{ Their meanings } & \multicolumn{2}{|c|}{ Percentage $\%$} & \multirow{2}{*}{$\begin{array}{c}\text { Mean of total } \\
\text { answers } \%\end{array}$} \\
\hline & & Advanced & Intermediate & \\
\hline \multirow{5}{*}{ Open } & Meaning 1: 'spread out' & $96 \%$ & $96 \%$ & $96 \%$ \\
\hline & Meaning 2: 'not covered' & $36 \%$ & $24 \%$ & $30 \%$ \\
\hline & Meaning 3: 'honest' & $40 \%$ & $12 \%$ & $26 \%$ \\
\hline & Meaning 4: 'not hidden' & $0 \%$ & $0 \%$ & $0 \%$ \\
\hline & Meaning 5: 'available’ & $88 \%$ & $64 \%$ & $76 \%$ \\
\hline \multirow{5}{*}{ Run } & Meaning 1: 'to move fast' & $96 \%$ & $80 \%$ & $88 \%$ \\
\hline & Meaning 2: 'manage' & $36 \%$ & $28 \%$ & $32 \%$ \\
\hline & Meaning 3: 'provide' & $24 \%$ & $12 \%$ & $18 \%$ \\
\hline & Meaning 4: 'use' & $72 \%$ & $12 \%$ & $42 \%$ \\
\hline & Meaning 5: 'flow' & $12 \%$ & $0 \%$ & $6 \%$ \\
\hline \multirow{5}{*}{ Make } & Meaning 1: 'prepare' & $92 \%$ & $80 \%$ & $86 \%$ \\
\hline & Meaning 2: 'force' & $12 \%$ & $20 \%$ & $16 \%$ \\
\hline & Meaning 3: 'appoint' & $36 \%$ & $8 \%$ & $22 \%$ \\
\hline & Meaning 4: 'reach' & $12 \%$ & $0 \%$ & $6 \%$ \\
\hline & Meaning 5: 'represent' & $72 \%$ & $32 \%$ & $52 \%$ \\
\hline \multicolumn{2}{|c|}{ Mean of total answers $\%$} & $48.2 \%$ & $31.2 \%$ & $39.7 \%$ \\
\hline
\end{tabular}

A careful study of Table 2 reveals five results: firstly, ALs outperformed their ILs counterparts on the test; the overall percentage of the correct answers provided by ALs was $48.26 \%$, while that of the correct answers provided by ILs was $31.2 \%$. Secondly, the total average $(39.7 \%)$ of both ALs $(48.2 \%)$ and ILs $(31.2 \%)$ was below the passing average (50\%), which indicates their little awareness of polysemy in English. Thirdly, the primary meaning of the polysemous words marked the highest percentages of correct answers provided by both ALs and ILs. Fourthly, it seems that the extended meanings gave both groups a difficult time; the percentages of the extended meanings were low, apart from (meaning\#5) of the polysemous word open, in terms of which the percentages were high. Another exception is concerned with ALs only; the percentage of correct answers of either extended meaning (meaning\#4 or meaning\#5) of the polysemous words run and make, respectively, was high. Finally, both groups scored zero (either because no answer was provided or because the provided answer was incorrect) in terms of the extended meaning (meaning\#4) of the polysemous word open. However, only ILs scored zero in terms of the extended meanings (meaning\#5 and meaning\#4) of the polysemous words run and make, respectively.

To determine whether the English proficiency level of the participants played a role in their performance on the translation test, a t-test was employed. The results of this test are presented in Table 3. 
Table 3. Results of t-test of correct answers between ALs and ILs on the translation test

\begin{tabular}{llllll}
\hline $\begin{array}{l}\text { English } \\
\text { proficiency } \\
\text { level }\end{array}$ & Number & Mean & T value & $\begin{array}{l}\text { Degree of } \\
\text { freedom }\end{array}$ & Sig. \\
\hline ALs & 25 & 48.26 & 3.76471 & 2 & $.009847^{*}$ \\
\hline ILs & 25 & 31.20 & & & \\
$* \mathrm{p}>0.05$ & & & & &
\end{tabular}

Table 3 shows that there were statistically significant differences between the correct answers provided by ALs and ILs on the test; $p$ value was lower than 0.05. This suggests that the English proficiency level of the participants played a role in their performance on the test. That is, ALs outperformed ILs.

In order to test the two hypotheses mentioned in section 3.3, two t-tests were used. The first test was employed to determine whether there were statistically significant differences between the answers of ALs and those of ILs in terms of the primary meaning (meaning\#1) of the three words open, run, and make. The second t-test was used to determine whether there were statistically significant differences between the answers of ALs and those of ILs in terms of the extended meanings (meaning\#2, meaning\#3, meaning\#4, and meaning\#5) of the three target words open, run, and make. Table 4 shows the results of the first t-test, which examines H1 and Table 5 presents the results of the second ttest, which investigates $\mathrm{H} 2$.

Table 4. Results of t-test examining H1

\begin{tabular}{llllll}
\hline $\begin{array}{l}\text { English } \\
\text { proficiency } \\
\text { level }\end{array}$ & Number & Mean & T value & $\begin{array}{l}\text { Degree of } \\
\text { freedom }\end{array}$ & Sig. \\
\hline ALs & 25 & 94.67 & 1.69775 & 2 & $.082395^{*}$ \\
\hline ILs & 25 & 85.33 & & & \\
$*_{\mathrm{p}<0.05}<0$ & & & &
\end{tabular}

Table 5. Results of t-test examining $\mathrm{H} 2$

\begin{tabular}{llllll}
\hline $\begin{array}{l}\text { English } \\
\text { proficiency } \\
\text { level }\end{array}$ & Number & Mean & T value & $\begin{array}{l}\text { Degree of } \\
\text { freedom }\end{array}$ & Sig. \\
\hline ALs & 25 & 36.67 & 1.98405 & 11 & $.029932^{*}$ \\
\hline ILs & 25 & 17.67 & & & \\
\hline $\mathrm{p}>0.05$ & & & & &
\end{tabular}

Table 4 demonstrates that H1 was confirmed; there were no statistically significant differences between the answers provided by both groups on the primary meaning of the three polysemous words ( $p$ value is higher than 0.05 ), which proposes that both groups had no problem with the primary meaning.

Table 5 shows that $\mathrm{H} 2$ was also confirmed; there were statistically significant differences between the answers provided by both groups on the extended meanings of the three polysemous words ( $p$ value is lower than 0.05), and a major difference of 19 between the mean of ALs $(M=36.67)$ and the mean of ILs $(M=17.67)$, which means that ALs outperformed their ILs counterparts in terms of the extended meanings of the three polysemous words.

\subsection{Discussion}

Pursuing an analytical approach, the data collected and the results obtained from the current study can be interpreted as follows. ALs outperformed ILs in the translation test because certainly their English proficiency level played a significant role as shown in the previous section. ALs were more exposed to English than ILs at the university level. As mentioned in section 3, ALs were enrolled in a module called Effective Communication Skills in English 2, the prerequisite of which is a module called Effective Communication Skills in English 1. The nature of the English ALs were exposed to in these two modules was more sophisticated than that of the module ILs were taking. ALs had to study new vocabulary in a variety of contexts, and they were even encouraged to productively use what they learnt through speaking and writing activities. This, perhaps, enhanced their acquisition of English vocabulary, in general, and of polysemy, in particular. It should not be denied that the dedication of ALs and their efforts to learn English outside the university helped take their English to a higher level, in contrast to ILs, and that can be inferred from the IELTS scores of both groups of learners. Although ALs outperformed their ILs counterparts in the translation test, it can be 
argued that both ALs and ILs exhibited little awareness of polysemy in English. This stems from the fact that most teachers at schools or university do not alert learners to the polysemic nature of most English words; they only teach them the primary meaning of the polysemous words. Although learners may encounter polysemous words in various activities and tasks at school or university, they are not being familiarised with polysemy as a phenomenon. However, teachers are not the only ones to blame; it seems that most Arabic-speaking EFL learners are not interested in learning such a lexical phenomenon notwithstanding its significance in understanding the full dimensions, subtlety, versatility, and shades of meanings inherent in the English language.

Since this study was conducted in the UAE, an important fact that needs to be taken into account is that the instruction and the use of English receptive and productive skills of polysemy are not emphasised in English-subject curriculum in the UAE.

Based on the results obtained from this study, both ALs and ILs had no problems comprehending the primary meaning of the English polysemous words open, run, and make, and then producing their accurate Arabic equivalent. Nevertheless, it seems that both ALs and ILs faced some problems when translating the extended meanings resulting in significant differences between the answers of both groups. This finding is in accord with one of Wei and Lou's (2015) results in which they specifically indicated that Chinese EFL learners of different English proficiency levels showed similar acquisition effects in the primary meaning of polysemous words but different acquisition effects in the extended ones.

The accuracy of the answers of both groups was on the account of the fact that at school, Arabic-speaking EFL learners, as is mentioned before, are taught and trained on using only the primary meaning of the polysemous words. This suggests that the primary meaning becomes easily acquired by Arabic-speaking EFL learners due to its being frequently encountered in contexts that require this meaning. Thus, the Arabic equivalent of the primary meaning of the three target words was the first to be recalled and produced by both ALs and ILs. Another reason for the accuracy in the answers of both groups was that the three polysemous words were embedded in simple contexts that were easy to understand and access and were free of any ambiguity, as shown below:

1) The flowers are all open now.

2) Can you run as fast as Mike?

3) She made coffee for all of us.

However, this accuracy started to decrease when the learners encountered the same polysemous words in other unfamiliar contexts. Some of the learners paid no attention to the context, interpreting a polysemous word by its primary meaning where the extended meaning is required. EFL learners, as Laufer (1997) stated, are reluctant to abandon the primary meaning even when it makes no sense in a context. For example, some learners in this study translated the polysemous word open in 'She was always open to her parents' by its primary meaning as (مَفتُوحَة) and

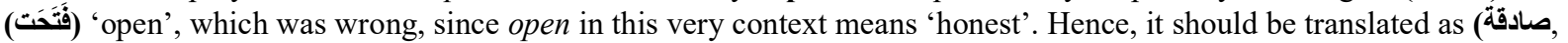
(صريحة), or whatever word which conveys the same meaning).

The same problem occurred when the participants were asked to translate (meaning\#2) and (meaning\#3) of the polysemous word make; instead of translating make in 'They made me repeat the whole story' and 'She made him her

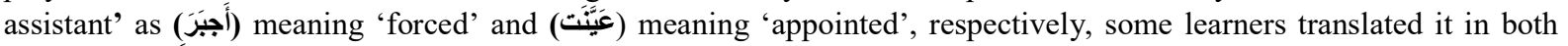
contexts as (صنَعَ) which means 'create'. This can be a result of not knowing the meaning of some words surrounding the target polysemous words. Some learners, for instance, did not understand the meaning of Dover, van, and diesel in the sentences 'Do you think we will make Dover by 12?' and 'Our van runs on diesel', so they translated make, which was the target polysemous word in these two sentences, by its primary meaning.

Moreover, some learners mistook some words for others, resulting in the misunderstanding of the whole context, and in turn, in the mistranslation of the polysemous word the meaning of which is determined by the context. In the sentence 'The hall of the old house was open to the sky', some learners mistook the word hall for hole (as these two words are pronounced the same with a difference in the vowel sound), thinking that the house has a roof but with a hole (an open gap) in it. This contradicts the original meaning of the sentence that the hall is roofless and leads to the translation of the primary meaning of open.

With regard to the extended meaning (meaning\#4) of the polysemous word open, no correct answers were provided by either group of learners. The sentence in which open can be interpreted as not hidden or clear was 'His eyes showed open admiration as he looked at her'. Again, some learners interpreted open by its primary meaning, while others translated the sentence without even providing an equivalent for open. Perhaps they thought that the verb showed was sufficient to render the meaning; for if there is admiration, it must be clear. Moreover, some learners wanted to avoid

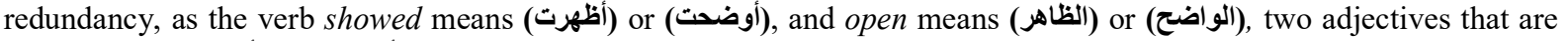
derived from (أوضح and أظهر and Hence, they avoided repeating the same meaning. However, as long as no Arabic equivalent for open was provided, the answer is considered wrong.

Although (meaning\#5) of open is an extended meaning, the percentage of the correct answers provided by both group of learners regarding this meaning is high. The sentence used in the test was 'What options are open to us?'. In fact, learners are familiar with this context; they encounter it in their daily lives whenever different options are available: when registering for a module at the university, or when booking a seat in a plane or a room in a hotel, not necessarily only in classroom activities. Thus, frequent incidental encounters of the extended meanings can lead to the acquisition of these meanings. The percentages of the correct answers provided regarding the extended meaning (meaning\#5) of the 
polysemous word run are very low (ALs $=12 \%, \mathrm{ILs}=0 \%$ ). Most of the learners translated ran in 'The tears ran down her cheeks' as fell (سقطت), which is considered wrong. This may be partly attributed to the participants' lack of high competency in Arabic although they are university students, who are supposed to have demonstrated a higher level of precession of expression. They must have confused (سالت الدموع) meaning 'tears ran down' with (سقطت الدموع) meaning 'tears fell', which is more frequently used in Arabic expressions.

The context in which the extended meaning (meaning\#5) of the polysemous word make seemed somehow awkward or unusual is: 'You have made my nose too big.' But since a cue which was [For example: in a drawing] was provided, the learners who understood the cue guessed the meaning of make, hence, provided accurate translations, such as (كبرت أنفي في الرسم) You have made my nose too big'. However, those who did not understand the cue,

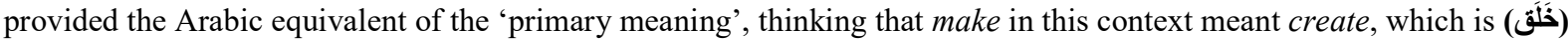
or (صنَع). It could be inferred that when more information about a context is provided, the context becomes more understandable, and the meaning of a polysemous word more accessible. This result supports Kim and Choe's (2015) suggestion that differences in second-language learners' knowledge can be measured not only by how many individual meanings they have memorised, but also by their ability to use contextual cues.

\section{Conclusion and recommendations}

To sum up, Arabic-speaking EFL learners have little awareness of polysemy in English. This could be due to three reasons: (1) teachers at school do not alert students to the phenomenon of polysemy; (2) no emphasis is given to the instruction and the use of English receptive and productive skills of polysemy in the English-subject curriculum; and (3) students find it quite challenging to learn lexical phenomena in L2 among which is polysemy. Nevertheless, it is confirmed that the participants' English proficiency level plays an important role in their ability to differentiate between the various meanings of polysemous words, as advanced learners outperformed intermediate learners on the test.

The statistical results obtained from the test show that both advanced learners and intermediate learners have no problems accessing the primary meaning of the polysemous words open, run, and make. However, both groups of learners face some problems comprehending the extended meanings of these words and then producing their Arabic equivalent due to some factors, such as: (1) lacking knowledge of the meaning of some words surrounding the target polysemous words, thus, providing the Arabic equivalent of the 'primary meaning', (2) sticking to the primary meaning and paying no attention to the context, and (3) mistaking some words for others which, in turn, changes the intended meaning of the context on which the meaning of the polysemous word is dependent. Some learners misinterpreted some polysemous words for want of high competency in the mother tongue, which leads to confusing the target meaning of the context with the one erroneously used in the mother tongue.

An interesting finding is that when more information about a context is provided, guessing the extended meaning of the target polysemous word becomes easier. The extra information in this test was a cue provided in one sentence, and it did help learners, though not all, access the target polysemous word. Furthermore, it is found that learners can translate the extended meanings of the polysemous words in familiar and frequently encountered contexts.Subsequently, it is recommended that curriculum developers and teachers alike work hand in hand to increase students' awareness of the phenomenon of polysemy and the polysemic nature of most English words by emphasising the receptive and productive use of polysemy in English-subject curriculum. It is also recommended that teachers implement extensive reading programmes by providing students with interesting and compelling reading materials that allow for multiple and frequent encounters of vocabulary in different contexts, leading to the acquisition of vocabulary, in general, and of polysemous words, in particular. Krashen $(1989$, 2003, 2004) suggests that through extensive reading, especially sustained silent reading, students would simply acquire the words incidentally, or without intention or instruction, over time. Since motivation in second language acquisition, as Oller et al. (1977) argue, is very important, teachers should motivate students to acquire English polysemous words. Teachers can show students how crucially important the acquisition of polysemous words is for using English both receptively and productively with great efficiency, and for developing their communicative skills which is the ultimate goal of every EFL learner. Finally, it is recommended that further studies are needed to explore the acquisition of other lexical phenomena by Arabic-speaking EFL learners, such as compounds (see Altakhaineh, 2016). Such studies can improve Arabic-speaking EFL learners' understanding of the processes of second language acquisition as far as vocabulary is concerned.

\section{Acknowledgements}

This paper could not have come to fruition without the invaluable help and support of my teacher and supervisor Dr. Abdel Rahman Altakhaineh. For that, he deserves all my respect and gratitude. My thanks are also extended to the students who took part in this study. Any errors are entirely mine.

\section{References}

Altakhaineh, A. R. M. (2016). Identifying Arabic compounds other than the Synthetic Genitive Construction. Acta Linguistica Hungarica,63(3), pp. 277-298. Retrieved on $14^{\text {th }}$ January 2017 from http://dx.doi.org/10.1556/064.2016.63.3.1

Armstrong, N. (2005). Translation, linguistics, culture: A French-English handbook. Multilingual matters. 
Bensoussan, M. Laufer, B. (1984). Lexical guessing in context in EFL reading comprehension. Journal of Research in Reading, 7(1), pp. 15-32.

Christiane, D. Fellbaum. (2000). Autotroponymy. In, Y. Ravin \& C. Leacock (eds.) Ploysemy: Theoretical and Computational Approaches (pp. 52-67). New York: Oxford University Press.

Cobb, T. (2006). The old vocabulary, the new vocabulary, and the Arabic learner. Paper version of vocabulary symposium presentation TESOL Arabia. Dubai, March 2006.

Dash, N. S. (2008). Context and contextual word meaning. SKASE Journal of Theoretical Linguistics, 5(2), pp. 21-31.

Dash, N. S. (2010). Polysemy and Homonymy: A Conceptual Labyrinth. IndoWorrdnet-2010, Dept. of Computer Science and Engineering, IIT, Kharagpur, 8th December.

Durkin, K., \& Manning, J. (1989). Polysemy and the subjective lexicon: Semantic relatedness and the salience of intraword senses. Journal of Psycholinguistic Research, 18(6), pp. 577-612.

Gyori, G. (2002). Semantic change and cognition. Cognitive Linguistics, 13(2), pp. 123-166.

Hamlaoui, M. H. (2010). Ambiguity of Polysemous English Words in Translation: The Case of Second Year Students at the University of Constantine (Doctoral dissertation, Ministry of Higher Education).

Hulstijn, J. (1998). Incidental vocabulary acquisition in a second language. Applied Linguistics, 22, pp. 1-26.

Hulstijn, J. (2001). Some empirical evidence for the involvement load hypothesis in vocabulary acquisition. Language Learning, 51(3), pp. 539-558. Retrieved on $12^{\text {th }}$ January 2017 from http://dx.doi.org/10.1111/0023-8333.00164.

Iravani, H., \& Ghasemi, M. D. (2012). A comparison of using three different types of cues, elaborated context, semantic frames and meaning chains, in disambiguating polysemous verbs. International Journal of English Language Education, 1(1), pp. 109-129. Retrieved on 14 ${ }^{\text {th }}$ January 2017 from https://doi.org/10.5296/ijele.v1i1.2956

kim, Y., \& Choe, M. (2015). Korean EFL learners knowledge of polysemous words in relation to word frequency and reading proficiency. 현대영어영문학 [Modern Studies in English Language \& Literature] 59(3), pp.125-146.

Kovacs, E. (2011). Polysemy in traditional vs. cognitive linguistics. Eger Journal of English Studies, XI, pp. 3-19.

Krashen, S. (1989). We acquire vocabulary and spelling by reading: Additional evidence for the input hypothesis. The Modern Language Journal, 73(4), pp. 440-464.

Krashen, S. (2003). Explorations in Language Acquisition and Use. Portsmouth, NH: Heinemann.

Krashen, S. (2004). The Power of Reading: Insights from the Research. Portsmouth, NH: Heinemann.

Laufer, B. (1997). What's in a word that makes it hard or easy? In N. Schmitt and M. McCarthy (eds.) Intralexical Factors Affecting the Difficulty of Vocabulary Acquisition. Vocabulary: Description, Acquisition and Pedagogy (pp. 140-155). Cambridge: Cambridge University Press.

Liu, D. (2013). Describing and Explaining Grammar and Vocabulary in ELT: Key Theories and Effective Practices. London: Routledge.

Makni, F. (2013). Teaching Polysemous Words to Arab Learners: A Cognitive Linguistics Approach (Doctoral dissertation, University of the West of England).

Morimoto, S. \& Loewen, S. (2007). A comparison of the effects of image-schema-based instruction and translationbased instruction on the acquisition of L2 polysemous words. Language Teaching Research, 11(3), pp. 347-372.

Murphy, G. L. (2004). The Big Book of Concepts. Cambridge, MA: MIT Press.

Nation, I. S. \& Beglar, D. (2007). A vocabulary size test. The Language Teacher 31(7), pp. 9-13.

Nation, I. S. P. (1990). Teaching and learning vocabulary. Boston,Massachusetts: Newbury House.

Nation, I. S. P. (2001). Learning Vocabulary in another Language. Cambridge: Cambridge University Press. Retrieved on $23^{\text {rd }}$ Feb 2017 from http://dx.doi.org/10.1017/CBO9781139524759.

Nation, P. (2008). Teaching vocabulary: Strategies and techniques. Boston: Heinle.

Oller, D. K., \& Smith, B. L. (1977). Effect of final-syllable position on vowel duration in infant babbling. The Journal of the Acoustical Society of America, 62(4), pp. 994-997.

Parent, K. (2009). Polysemy: A Second Language Pedagogical Concern. New Zealand: Victoria University of Willington.

Reynolds, B. L., Wu, W. H., Liu, H. W., Kuo, S. Y., \& Yeh, C. H. (2015). Towards a model of advanced learners' vocabulary acquisition: An investigation of L2 vocabulary acquisition and retention by Taiwanese English majors. Applied Linguistics Review, 6(1), pp. 121-144.

Salem, A. S. M. (2014). The Role of Context in Solving the Problems of Translating Polysemous English Words into Arabic (Masters Dissertation). Retrieved on $13^{\text {th }} \quad$ Feb 2017 from https://researchgate.net/publication/301769363_The_Role_of_Context_in_Solving_the_Problems_of_Translating_Poly semous_English_Words_into_Arabic. 
Shohamy, E. (1984). Does the testing method make a difference? The case of reading comprehension. Language Testing, 1(2), pp. 147-170. Retrieved on $12^{\text {th }}$ December 2016 from http://dx.doi.org/10.1177/026553228400100203

Ullmann, S. (1959). Semantics: An Introduction to the Science of Meaning. Oxford: Blackwell.

Wehmeier, S. (2007). New Oxford Advanced Learner's Dictionary. Oxford: Oxford University Press.

Wei, X., \& Lou, Y. (2015). A study of word meaning acquisition of polysemous words for English majors. Creative Education, 6(18).

Yule, G. (2010). The Study of Language. 4th ed. Cambridge: Cambridge University Press.

Zibin, A. (2016). On the production of metaphors and metonymies by Jordanian EFL learners: Acquisition and implications. Topics in Linguistics, 17(2), pp. 41-58. Retrieved on $12^{\text {th }}$ January 2017 from https://doi.org/10.1515/topling-2016-0012

Zibin, A. and Altakhaineh, A. R. M. (2016). Acquiring the English causative alternation: Evidence from the University of Jordan. International Journal of Applied Linguistics and English Literature, 5(3), pp.7-15. Retieved on $23^{\text {rd }}$ February 2017 from https://doi.org/10.7575/aiac.ijalel.v.5n.3p.7

Zibin, A. and Altakhaineh, A. R. M. (2014). Informativity of Arabic proverbs in context: An insight into Palestinian discourse. International Journal of Linguistics, 6(1), pp.67-83. Retrieved on $12^{\text {th }}$ Decmeber 2016 from https://doi.org/10.5296/ijl.v6i1.4857

\section{Appendix A}

\section{The Test}

Course title:

IELTS Score:

Q1: Translate the following sentences into Arabic.

1. The flowers are all open now.

2. Can you run as fast as Mike?

3. $\quad$ She made coffee for all of us.

4. The hall of the old house was open to the sky.

5. He has no idea how to run a business.

6. They made me repeat the whole story.

7. She was always open to her parents.

8. The college runs summer courses for foreign students.

9. $\quad$ She made him her assistant.

10. His eyes showed open admiration as he looked at her.

11. Our van runs on diesel.

12. Do you think we will make Dover by 12 ?

13. What options are open to us?

14. The tears ran down her cheeks.

15. You have made my nose too big. [For example: in a drawing] 